\title{
On Finite Time Delay Dependent Stability of Linear Discrete Delay Systems: Numerical Solution Approach
}

\author{
Dragutin Debeljković ${ }^{1)}$ \\ Aleksandar Cvetković ${ }^{2)}$ \\ Ivan Buzurović ${ }^{3)}$ \\ Milan Mišić ${ }^{4}$ \\ Vladimir Janković ${ }^{5)}$
}

\begin{abstract}
In this paper, a possible solution of the basic nonlinear quadratic matrix equation was proposed. The solution is crucial in the formulation of the particular criteria for the delay-dependent finite time stability of discrete time delay systems represented as $\mathrm{x}(k+1)=A_{0}(k)+A_{1} \mathrm{x}(k-h)$. The time delay-dependent criteria have been derived. In addition, the significance of the nonlinear discrete polynomial matrix equation is explained. With the use of the mathematical formalism based on the Traub and Bernoulli's algorithms, it was concluded that the computation of the dominant solvent of the matrix polynomial equation does not guarantee a necessary convergence in all cases, unlike in the traditional numerical procedures. In this paper, we presented one particular and one general solution valid in the case when the discrete matrix equation was presented in its factorial form. The numerical computations are performed to illustrate the suggested results.
\end{abstract}

Key words: discrete system, linear system, time delay system, system stability, finite time stability system, discrete mathematics, particular solution, numerical result.

\section{Introduction}

$\mathrm{T}_{\mathrm{i}}^{\mathrm{o}}$ investigate the stability of a control system, the Lyapunov method was widely used in the control system community. In some cases, the Lyapunov stability is insufficient to describe the dynamical behavior of the special classes of the systems or to give satisfactory conclusions about the different types of stability. This is the case for the finite time stability in which the requirements are set on the states of the system. In these situations, there are constraints on the system states trajectories, i.e. they have to stay within the predefined values and should not exceed them. Consequently, there are requirements to investigate the trajectories of the system only over a finite time interval. Based on the stability investigation in a limited time frame, the described stability concept is named finite-time stability the (FTS). In that sense, the system is stable if the states of the system do not exceed the predefined boundaries on some fixed time interval. This stability concept was introduced in the era of modern control systems [1-6], and it is still widely used nowadays.

Time delay is often present in the electrical, mechanical, chemical, and other systems. The described latency in such systems can potentially bring the systems into instability, or its appearance can result in low performances during the transient process. Using the linear matrix inequalities (LMI) and the Lyapunov-like functional together with other approaches, many results for time-delay systems have been reported in the recently published literature.

In this article, we present the concept of the finite time stability of discrete time-delay systems previously investigated in [7].

A novel discrete Lyapunov-like functional with a discrete convolution of the delayed states was used for the stability investigations in that paper. The methodology used there was to combine the Lyapunov-like approach and the Jensen's discrete inequality. The novel sufficient stability conditions were presented in a form of algebraic inequalities with a necessity of solving the particular quadratic discrete matrix equation with the defined matrix $A$.

\section{Notations and preliminaries}

Notations: The matrix transposition was denoted by a superscript "T". $\mathbb{R}^{n}$ and $\mathbb{R}^{n \times m}$ are the $n$-dimensional Euclidean spaces and the set of all real matrices having dimension $(n \times m)$, respectively. $\lambda_{\max }(X), \lambda_{\min }(X)$ denotes the maximum (minimum) of eigenvalues of a real symmetric matrix $X$.

\footnotetext{
1) University of Belgrade, Faculty of Mechanical Engineering, Department of Control Engineering, Kraljice Marije 16, 11020 Belgrade 35, SERBIA

2) University of Belgrade, Faculty of Mechanical Engineering, Department of Mathematics, Kraljice Marije 16, 11020 Belgrade 35, SERBIA

3) Harvard Medical School, Medical Physics and Biophysics Division, Boston, MA, USA

4) University of Pristina, Faculty of Technical Science, Knjaza Miloša 7, 38220 Kosovska Mitrovica, SERBIA

5) Belgrade Waterworks and Sewerage System, Kneza Miloša 28, 11000 Belgrade, SERBIA

Correspondence to: Dragutin Debeljković; e-mail: ddebeljkovic@mas.bg.ac.rs
} 


\section{Problem formulation}

A linear discrete time system with a state delay was analyzed. The system is described as:

$$
A_{0} \mathbf{x}(k+1)=A_{1} \mathbf{x}(k)+A_{2} \mathbf{x}(k-h)
$$

with a known vector function of the initial conditions:

$$
\mathbf{x}(j)=\boldsymbol{\psi}(j), \quad j \in\{-h,-h+1, \ldots, 0\}
$$

Where $\mathbf{x}(k) \in \mathbb{R}^{n}$ is a state vector, $A_{1} \in \mathbb{R}^{n \times n}$ and $A_{2} \in \mathbb{R}^{n \times n}$ are known constant matrices, $h$ is a constant delay.

The initial condition $\psi(k)$ is the a priori known vector function for each $k \in\{-h,-h+1, \cdots, 0\}$

Definition 1. The linear discrete time-delay system (1), which satisfies the initial condition (2), is said to be finitetime stable with respect to $\{\alpha, \beta, N\}, \alpha<\beta$ if

$$
\begin{aligned}
& \sup _{k \in\{-h,-h+1, \cdots, 0\}} \boldsymbol{\psi}^{T}(k) \boldsymbol{\psi}(k) \leq \alpha \Rightarrow \\
& \mathbf{x}^{T}(k) \mathbf{x}(k)<\beta, \forall k \in\{1,2, \cdots, N\}
\end{aligned}
$$

Theorem 1. The linear discrete time delay system (1) with $A_{0}=I, I$ being identity matrix, satisfying:

$$
\begin{gathered}
\mathbf{x}^{T}(k-j) \mathbf{x}(k-j)<q \mathbf{x}^{T}(k) \mathbf{x}(k), \\
q>0, \quad j \in\{-h,-h+1, \ldots, 0\}, \quad \forall k \in\{1,2, \cdots, N\}
\end{gathered}
$$

is finite-time stable with respect to $\{\alpha, \beta, N\}, \alpha<\beta$, if there exist two positive scalars, $\mu$ and $\varepsilon$, such that:

$$
\begin{aligned}
& \frac{1+\mu h+\mu^{-1} \delta+h \delta}{1-\varepsilon h-\varepsilon^{-1} q \delta} \gamma^{N}<\frac{\beta}{\alpha}, \quad \varepsilon \in\left(\max \left\{\varepsilon_{1}, 0\right\}, \quad \varepsilon_{2}\right), \\
& \varepsilon_{1,2}=\frac{1 \pm \sqrt{1-4 q \delta h}}{2 h}, \quad q \delta h<1 / 4, \quad \delta_{i}>0, \quad i=1,2, \cdots, h
\end{aligned}
$$

where:

$$
\begin{gathered}
\gamma=\lambda_{\max }\left(A^{T} A-I\right)+1, \\
\delta_{i}=\lambda_{\max }\left\{\left(A-A_{1}\right)^{T}\left(A^{j-1}\right)^{T} A^{j-1}\left(A-A_{1}\right)\right\}, \\
\delta=\sum_{j=1}^{h} \delta_{i}
\end{gathered}
$$

with matrix $A$ as a solution of:

$$
A^{h+1}-A^{h} A_{1}-A_{2}=0,
$$

as in [7].

The unavoidable problem, in order to examine the finite time stability of system given (1), is to solve the discrete matrix polynomial equation (7) upon the matrix $A$.

We denote by $\mathrm{M}_{m n}$ the linear space of all complex matrices of type $(n \times m)$ and by $\mathrm{M}_{n}$ the linear space of all complex quadratic matrices of $n$ order. We use 1 to denote the identity matrix in $\mathrm{M}_{n}, n \in \mathbb{N}$. If the ambiguity is possible we denote the identity matrix $1_{n} \in \mathrm{M}_{n}$.

In order to be able to formulate the results of the paper we need some definitions.

Definition 1. Spectrum of the matrix $X \in \mathrm{M}_{n}$ we denote by $\sigma(X)$. Set of the eigenvectors associated to the eigenvalue $\lambda \in \sigma(X)$ is denoted by $V_{\lambda}(X)$. Algebraic multiplicity of the eigenvalue $\lambda \in \sigma(X)$ is denoted by $k_{\lambda}(X)$.

Geometric multiplicity of the eigenvalue $\lambda \in \sigma(X)$, i.e., dimensionality of the space $V_{\lambda}(X)$, is denoted by $g_{\lambda}(X)$.

Let linear discrete time-delay system be represented by the equation:

$$
\begin{gathered}
A_{0} \mathbf{x}(k+1)=A_{1} \mathbf{x}(k)+A_{2} \mathbf{x}(k-1) \\
\mathbf{x}(-1), \mathbf{x}(0) \in \mathrm{M}_{n, 1}
\end{gathered}
$$

The system is described by the matrices $A_{0}, A_{1}$ and $A_{2}$, which belong to the space $\mathrm{M}_{n}$, and by the initial conditions $\mathbf{x}(-1)$ and $\mathbf{x}(0)$. Matrix $A_{0}$ is usually invertible, so that the system can be described in its equivalent form:

$$
\begin{gathered}
\mathbf{x}(k+1)=A_{0}^{-1} A_{1} \mathbf{x}(k)+A_{0}^{-1} A_{2} \mathbf{x}(k-1) \\
=A_{1}^{M} \mathbf{x}(k)+A_{2}^{M} \mathbf{x}(k-1)=\mathbf{0} \\
\mathbf{x}(-1), \mathbf{x}(0) \in \mathrm{M}_{n, 1}
\end{gathered}
$$

We are interested in studying the stability criterion of this dynamical system.

The main tool in our research is the following equivalent representation of the dynamical system.

Lemma 1. Dynamical system, described by the equation (1) is equivalent to the following dynamical system:

$$
\begin{gathered}
\mathbf{x}_{e q}(k+1)=A_{e q} \mathbf{x}_{e q}(k) \\
\mathbf{x}_{e q}(k)=\left[\begin{array}{ll}
\mathbf{x}^{T}(k-1) & \mathbf{x}^{T}(k)
\end{array}\right]^{T} A_{e q}=\left(\begin{array}{cc}
0 & 1 \\
A_{2}^{M} & A_{1}^{M}
\end{array}\right)
\end{gathered}
$$

Proof. The proof is rather obvious and will be omitted.

We can easily develop the stability criterion of the dynamical system described by (10). Actually, it is a linear system without time-delay, and the system is stable if and only if all the eigenvalues of the matrix $A_{e q}$ are in modulus equal to or less than 1 .

Lemma 2. Dynamical system (10) is stable if and only if for every $\lambda \in \sigma\left(A_{e q}\right)$ we have $|\lambda| \leq 1$.

The primer interest in this short paper is the algorithm for the numerical solution of the following quadratic equation:

$$
P(X)=A X^{2}+B X+C=0, \quad A, B, C \in \mathrm{M}_{n}
$$

over the set $\mathrm{M}_{n}$.

The case when the matrix $A$ is invertible is simpler, since, in this case we can multiply from the left with $A^{-1}$, and get a simplified equation:

$$
\begin{aligned}
P_{M}(X) & =X^{2}+A^{-1} B X+A^{-1} C \\
& =X^{2}+B_{M} X+C_{M}
\end{aligned}
$$

This equation is somewhat easier to handle, and some stronger results can be given in this case.

Definition 2. Let $X \in \mathrm{M}_{n}$ be such that $P(X)=0$. Then we call $X$ the (right) solvent of (11).

The set of all solvents of the equation (11) is denoted 
by $S(P)=\{X \mid P(X)=0\}$.

Definition 3. We denote by $\Omega(P)=\{\lambda \mid \operatorname{det}(P(\lambda))=0\}$ the set of complex values such that matrix $P(\lambda)$ is not invertible.

By $k_{\lambda}(P)$ we denote algebraic multiplicity of $\lambda \in \Omega(P)$.

The following simple Lemma gives motivation for the rest of the paper.

Lemma 3. Let $\lambda \in \sigma(X)$ and $X \in S(P)$ then $\lambda \in \Omega(P)$.

Proof.If $\lambda \in \sigma(X)$, then there exists $\mathbf{x} \in \mathbb{C}^{n} \backslash\{0\}$, such that $X \mathbf{x}=\lambda \mathbf{x}$. Consequently:

$$
\begin{aligned}
0 & =0 \mathbf{x}=P(X) \mathbf{x}=\left(A X^{2}+B X+C\right) \mathbf{x} \\
& =A X^{2} \mathbf{x}+B X \mathbf{x}+C \mathbf{x} \\
& =\lambda^{2} A \mathbf{x}+\lambda B \mathbf{x}+C \mathbf{x} \\
& =\left(\lambda^{2} A+\lambda B+C\right) \mathbf{x}=0
\end{aligned}
$$

it follows that $0 \neq \mathbf{x} \in \operatorname{ker}(P(\lambda))$. Hence, $P(\lambda)$ has nontrivial kernel, and is singular, and has a determinant equal to zero.

Lemma 4. Assume that $X \in S(P)$. Then the following factorization holds:

$$
P(\lambda)=-(A(X+\lambda)+B)(X-\lambda)
$$

Proof. Using the direct computation, we have:

$$
\begin{aligned}
-P(\lambda) & =P(X)-P(\lambda) \\
& =A X^{2}-\lambda^{2} A+B X-\lambda B \\
& =A(X+\lambda)(X-\lambda)+B(X-\lambda) \\
& =(A(X+\lambda)+B)-P(\lambda)(X-\lambda)
\end{aligned}
$$

which finishes the proof.

Theorem 1. We have:

$$
U_{X \in S(P)} \sigma(X) \subset \Omega(P)^{\tilde{C}}
$$

In general, we have $\Omega(P) \backslash U_{X \in S(P)} \sigma(X) \neq \varnothing$.

Let $\lambda_{i} \in \Omega(P), i=1, \ldots, n$, and let $\mathbf{x}_{i} \in \operatorname{ker}(P(\lambda))$, $i=1, \ldots, n$. If matrix $\oplus_{i=1}^{n} \mathbf{x}_{i}$ is regular then matrix:

$$
X=\left(\oplus_{i=1}^{n} \mathbf{x}_{i}\right) \operatorname{diag}\left\{\lambda_{1}, \ldots, \lambda_{n}\right\}\left(\oplus_{i=1}^{n} \mathbf{x}_{i}\right)^{-1}
$$

is the solution of the equation (6).

Let $X \in S(P)$ and $\mathbf{x} \in V_{\lambda}(X)$.

Then $\mathbf{x} \in \operatorname{ker}(P(\lambda))$.

Accordingly, $V_{\lambda}(X) \subset \operatorname{ker}(P(\lambda))$.

Proof. The first part of the Lemma is a direct consequence of the Lemma 3.

Consider:

$$
P(X)=X^{2}-\left(\begin{array}{lll}
0 & 1 & 0 \\
0 & 0 & 0 \\
0 & 0 & 1
\end{array}\right)
$$

Obviously we have $\operatorname{det}(P(\lambda))=\lambda^{2}(\lambda-1)$, i.e., $\Omega(\lambda)=\{0,1\}$.
However $S(P)=\{\}$, i.e., there is no solution to the equation $P(X)=0$.

The nonexistance of the solution can be proved using the Grobner basis techniques.

Assuming there exists a solution, we get the following system of algebraic equations:

$$
\begin{gathered}
x_{11}^{2}+x_{12} x_{21}+x_{13} x_{31}=0 \\
x_{11} x_{12}+x_{12} x_{22}+x_{13} x_{32}=1 \\
x_{11} x_{13}+x_{12} x_{23}+x_{13} x_{33}=0 \\
x_{11} x_{21}+x_{21} x_{22}+x_{23} x_{31}=0 \\
x_{12} x_{21}+x_{22}^{2}+x_{23} x_{32}=0 \\
x_{13} x_{21}+x_{22} x_{23}+x_{23} x_{33}=0 \\
x_{11} x_{31}+x_{21} x_{32}+x_{31} x_{33}=0 \\
x_{12} x_{31}+x_{22} x_{32}+x_{32} x_{33}=0 \\
x_{13} x_{31}+x_{23} x_{32}+x_{33}^{2}=1
\end{gathered}
$$

Using the Buchberger algorithm we get that the Groebner basis reduces to 1 , which clearly shows there is no solution.

The second part is obtained using direct computation:

$$
\begin{aligned}
& P(X)=A\left(\left(\oplus_{i=1}^{n} \mathbf{x}_{i}\right) \operatorname{diag}\left\{\lambda_{1}, \ldots, \lambda_{n}\right\}\left(\oplus_{i=1}^{n} \mathbf{x}_{i}\right)^{-1}\right)^{2} \\
& +B\left(\oplus_{i=1}^{n} \mathbf{x}_{i}\right) \operatorname{diag}\left\{\lambda_{1}, \ldots, \lambda_{n}\right\}\left(\oplus_{i=1}^{n} \mathbf{x}_{i}\right)^{-1}+C \\
& =\left(A\left(\oplus_{i=1}^{n} \mathbf{x}_{i}\right) \operatorname{diag}\left\{\lambda_{1}^{2}, \ldots, \lambda_{n}^{2}\right\}\right. \\
& \left.+B\left(\oplus_{i=1}^{n} \mathbf{x}_{i}\right) \operatorname{diag}\left\{\lambda_{1}, \ldots, \lambda_{n}\right\}+C\left(\oplus_{i=1}^{n} x_{i}\right)\right)\left(\oplus_{i=1}^{n} \mathbf{x}_{i}\right)^{-1} \\
& =\left(\oplus_{i=1}^{n}\left(\lambda_{i}^{2} A+\lambda_{i} B+C\right) \mathbf{x}_{i}\right)\left(\oplus_{i=1}^{n} \mathbf{x}_{i}\right)^{-1}=0\left(\oplus_{i=1}^{n} \mathbf{x}_{i}\right)^{-1}=0
\end{aligned}
$$

Suppose that $\mathbf{x} \in V_{\lambda}(X)$.

Using Lemma 4, we have:

$$
P(\lambda) \mathbf{x}=-(A(X+\lambda)+B)(X-\lambda) \mathbf{x}=0
$$

We conclude $\mathbf{x} \in \operatorname{ker}(P(\lambda))$.

Hence, we have $V_{\lambda}(X) \subset \operatorname{ker}(P(\lambda))$.

Clearly, the solutions which can be constructed using the previous Theorem include only the solutions which represent operators of the simple structure.

However, a matrix equation can have solutions which do not belong to this class.

Example. Consider the case in which:

$$
\begin{aligned}
P(X) & =\left(X-\left(\begin{array}{ll}
1 & 1 \\
0 & 1
\end{array}\right)\right)(X-1) \\
& =X^{2}-\left(\begin{array}{ll}
2 & 1 \\
0 & 2
\end{array}\right) X+\left(\begin{array}{ll}
1 & 1 \\
0 & 1
\end{array}\right)
\end{aligned}
$$

Obviously, we have at least two solutions:

$$
X=\left(\begin{array}{ll}
1 & 1 \\
0 & 1
\end{array}\right), \quad X=1
$$

However:

$$
\begin{aligned}
P(\lambda) & =\lambda^{2}-\lambda\left(\begin{array}{ll}
2 & 1 \\
0 & 2
\end{array}\right)+\left(\begin{array}{ll}
1 & 1 \\
0 & 1
\end{array}\right) \\
& =\left(\begin{array}{cc}
(\lambda-1)^{2} & -(\lambda-1) \\
0 & (\lambda-1)^{2}
\end{array}\right)
\end{aligned}
$$


We compute $\operatorname{det}(P(\lambda))=(\lambda-1)^{4}$, so that $\Omega(P)=\{1\}$, and:

$$
P(1)=\left(\begin{array}{ll}
0 & 0 \\
0 & 0
\end{array}\right)
$$

From here, we have $\operatorname{ker}(P(1))=\mathbb{C}^{2}$.

Choosing any two linearly independent vectors $\mathbf{x}_{1}$, $\mathbf{x}_{2} \in \mathbb{C}^{2}$, we get the solution $X=\left[\begin{array}{ll}\mathbf{x}_{1} & \mathbf{x}_{2}\end{array}\right] \operatorname{diag}\{1,1\}\left[\begin{array}{ll}\mathbf{x}_{1} & \mathbf{x}_{2}\end{array}\right]^{-1}=1$, i.e., we cannot construct the first solution.

Theorem 2. Assume that $\lambda_{1}, \lambda_{2} \in \Omega(P), \lambda_{1} \neq \lambda_{2}$, and that:

Then

$$
\mathbf{x} \in \operatorname{ker}\left(P\left(\lambda_{1}\right)\right) \cap \operatorname{ker}\left(P\left(\lambda_{2}\right)\right) .
$$

$$
\mathbf{x} \in \operatorname{ker}\left(\left(\lambda_{1}+\lambda_{2}\right) A+B\right) \text { and } \mathbf{x} \in \operatorname{ker}\left(-\lambda_{1} \lambda_{2} A+C\right) .
$$

If $\mathbf{x} \in \operatorname{ker}\left(\mu_{1} A+B\right)$ and $\quad \mathbf{x} \in \operatorname{ker}\left(\mu_{2} A+C\right)$ then $\mathbf{x} \in \operatorname{ker}\left(P\left(\lambda_{1}\right)\right) \cap \operatorname{ker}\left(P\left(\lambda_{2}\right)\right)$, where $\lambda_{1}$ and $\lambda_{2}$ are the solutions of the equation:

$$
\lambda^{2}-\mu_{1} \lambda-\mu_{2}=0
$$

Proof. We have $P\left(\lambda_{1}\right) \mathbf{x}=P\left(\lambda_{2}\right) \mathbf{x}=0$.

If we subtract these two equations we get:

$$
\begin{aligned}
\mathbf{0} & =\left(P\left(\lambda_{1}\right)-P\left(\lambda_{2}\right)\right) \mathbf{x} \\
& =\left(\lambda_{1}-\lambda_{2}\right)\left(\left(\lambda_{1}+\lambda_{2}\right) A+B\right) \mathbf{x}
\end{aligned}
$$

and conclude $\mathbf{x} \in \operatorname{ker}\left(\left(\lambda_{1}+\lambda_{2}\right) A+B\right)$.

Further:

$$
\begin{aligned}
\mathbf{0} & =\left(\lambda_{1}^{2} A+\lambda_{1} B+C\right) \mathbf{x} \\
& =\lambda_{1}\left(\left(\lambda_{1}+\lambda_{2}\right) A+B\right) \mathbf{x}+\left(-\lambda_{1} \lambda_{2} A+C\right) \mathbf{x} \\
& =\left(-\lambda_{1} \lambda_{2} A+C\right) \mathbf{x}
\end{aligned}
$$

We get the first part of the statement.

Let $\lambda$ be the solution of the equation $\lambda^{2}-\mu_{1} \lambda-\mu_{2}=0$.

We have:

$$
\begin{gathered}
\left(\lambda^{2} A+\lambda B+C\right) \mathbf{x}=\lambda\left(\mu_{1} A+B\right) \mathbf{x}+ \\
+\left(\lambda\left(\lambda-\mu_{1}\right)-\mu_{2} A\right) \mathbf{x}+\left(\mu_{2} A+C\right) \mathbf{x}= \\
=\left(\lambda^{2}-\mu_{1} \lambda-\mu_{2}\right) A \mathbf{x}=0 \mathbf{x}=\mathbf{0}
\end{gathered}
$$

which finishes the second part of the statement.

The previous Theorem can have a much simpler form if we assume that $A=1$.

Theorem 3. (Monic case) Assume that $\lambda_{1}, \lambda_{2} \in \Omega\left(P_{M}\right)$ $\lambda_{1} \neq \lambda_{2}$, and that $\mathbf{x} \in \operatorname{ker}\left(P_{M}\left(\lambda_{1}\right)\right) \cap \operatorname{ker}\left(P_{M}\left(\lambda_{2}\right)\right)$.

Then $\quad-\lambda_{1}-\lambda_{2} \in \sigma(B), \quad \mathbf{x} \in V_{-\lambda_{1}-\lambda_{2}}(B), \quad$ and $\lambda_{1} \lambda_{2} \in \sigma(C), \mathbf{x} \in V_{\lambda_{1} \lambda_{2}}(C)$.

If $\mu_{1} \in \sigma(B) \quad$ and $\quad \mu_{2} \in \sigma(C) \quad$ with $\mathbf{x} \in V_{\mu_{1}}(B) \cap V_{\mu_{2}}(C)$ then $\quad \mathbf{x} \in \operatorname{ker}\left(P\left(\lambda_{1}\right)\right) \cap \operatorname{ker}\left(P\left(\lambda_{2}\right)\right)$, where $\lambda_{1}$ and $\lambda_{2}$ are the solutions of the equation:

$$
\lambda^{2}+\mu_{1} \lambda+\mu_{2}=0
$$

\section{Numerical solution}

The presented numerical algorithm is developed in classical literature.

Numerical algorithm, used to solve the equation $P(X)=0$, is a modification of the Newton's algorithm adopted to solve nonlinear equations over $\mathrm{M}_{n}$.

In order to develop the algorithm we first need to expand $P$ at the point close to the solution $X$.

We have:

$$
\begin{gathered}
P(X+\Delta X)=A(X+\Delta X)^{2}+B(X+\Delta X)+C \\
=A X^{2}+A X \Delta X+A \Delta X X \\
+A(\Delta X)^{2}+B X+B \Delta X+C \\
=P(X)+A(X \Delta X+\Delta X X)+B \Delta X
\end{gathered}
$$

If we equate $P(X+\Delta X)$ with zeros and neglect the terms in $(\Delta X)^{2}$, we get the following equation for $\Delta X$ :

$$
\begin{gathered}
A(X \Delta X+\Delta X X)+B \Delta X \\
=(A X+B) \Delta X+A \Delta X X=-P(X)
\end{gathered}
$$

If we denote by $F_{X} \Delta X=(A X+B) \Delta X+A \Delta X X$, we can recognize $F: \mathrm{M}_{n} \rightarrow \mathrm{M}_{n}$ as a linear operator acting on the space $\mathrm{M}_{n}$. It is easily recognized as the Frechet derivative of the nonlinear operator $P: \mathrm{M}_{n} \rightarrow \mathrm{M}_{n}$. The Newton method goes as follows: choose $X_{0}$, and compute the sequence $X_{k+1}=X_{k}+\Delta X_{k}, k \in \mathbb{N}_{0}$, where $\Delta X_{k}$ is the solution of the equation $F_{X} \Delta X_{k}=-P\left(X_{k}\right), k \in \mathbb{N}_{0}$. The computation ends when we achieve requested precision $\left(X_{k+1}-X_{k}\right)<\varepsilon$.

However, there are some serious issues to be discussed which are connected to the computation of $\Delta X_{k}$.

We recognize that $F_{X} \Delta X=-P(X)$ is actually the Sylvester equation. As given in [1], we know that the Sylvester equation has a unique solution if and only if $\operatorname{det}(A(X+\lambda)+B) \neq 0, \quad \lambda \in \mathbb{R}$ and the solutions of $\operatorname{det}(A(X+\lambda)+B)$ are not the eigenvalues of $X$.

If $X \in S(P)$ then, according to the factorization given in Lemma 4, the Sylvester equation would have a solution if $n$ eigenvalues of $X$ do not belong to the remaining $n$ solutions of $P(\lambda)=0$, and if for example $A$ is nonsingular, in which case the polynomial $\operatorname{det}(A(X+\lambda)+B)$ has a degree $n$ and cannot be identically equal to zero.

This simple observation emphasizes the idea of maximal and minimal solutions.

Definition 4. The solution $X$ of the equation $P(X)$ is called maximal (minimal) if all the eigenvalues of $X$ are greater (smaller) in modulus than the solutions of $\operatorname{det}(A(X+\lambda)+B)=0$.

Maximal solution is also known in the literature as a dominant solution.

Lemma 5. Let $X$ be the solution of the equation $P(X)=0$, then Frechet derivative $F_{X}$ is regular.

Using the continuity argument, one can claim that there exists some neighborhood $O_{\varepsilon}(X)=\{Y \mid(X-Y)<\varepsilon\}$ of the maximal (minimal) solution $X$ such that the Frechet 
derivative $F_{X}$ is nonsingular.

That gives the argument to use the Newton method to solve such equations.

However, as we know the existence of the dominant solution is not always guaranteed.

\section{Numerical solution: the Sylvester equation}

The numerical method that solves the Sylvester equation has a long history and can be tracked back to the papers of classical literature.

Here we give the method only for the completeness.

First, we compute the generalized Schur decomposition of the matrices $A$ and $A X+B$.

Suppose, these are given by:

$$
\alpha^{*} A \beta=G, \quad \alpha^{*}(A X+B) \beta=H
$$

where $\alpha$ and $\beta$ are unitary matrices and $G, H$ are upper triangular. Let also $K=\gamma^{*} X \gamma$, be the Schur decomposition of $X$, with $\gamma$ being nitary and $K$ upper triangular.

Then our equation becomes:

$$
H \tilde{\Delta X}+G \tilde{\Delta X} K=-\alpha^{*} P(X) \gamma, \quad \tilde{\Delta X}=\beta^{*} \Delta X \gamma
$$

Assuming that $-\alpha^{*} P(X) \gamma=\left(p_{1}, \ldots, p_{n}\right) \quad$ and $\tilde{\Delta X}=\left(\mathbf{x}_{1}, \ldots, \mathbf{x}_{n}\right)$, by equating the columns we get:

$$
\left(H+k_{i i} G\right) \mathbf{x}_{i}=p_{i}-\sum_{l=1}^{i-1} k_{l i} G_{\mathbf{x}_{i}}, \quad i=1, \ldots, n, \quad K=\left(k_{i i}\right)
$$

As we can see we end up in a triangular system of equations, which can be solved easily.

\section{Modification of the Newton method}

According to the fact that in deriving the Newton method we neglected the terms of a higher order than the one in $\Delta X$, it is obvious that in some cases, $X_{k+1}$ can be worse approximation to the solution than $X_{k}$ was.

In order to avoid such scenario line searches are usually implemented in the Newton method.

In this case the Newton method reads as follows: choose $X_{0}$, then compute $X_{k+1}=X_{k}-t_{k} \Delta X_{k}, k \in \mathbb{N}_{0}$, where $\Delta X_{k}$, $k \in \mathbb{N}_{0}$, are the solutions to the Sylvester equation, and where parameters $t_{k} \in \mathbb{R}, k \in \mathbb{N}_{0}$, are suitably chosen according to some criterion.

Actually, this modification uses the direction of $\Delta X_{k}$ for computation of $X_{k+1}$, however, it does not allow for the correction to be too strong.

Natural candidate for the parameter $t_{k}$, is the one which minimizes the norm:

$$
p_{k}(t)=\left\|P\left(X_{k}+t \Delta X_{k}\right)\right\|^{2}
$$

Various matrix norms can be used to define the function $p_{k}$. However, the particular choice of the Frobenius norm
$\|A\|=\left(\operatorname{trag}\left(A^{*} A\right)\right)^{1 / 2}$ is preferable in order to be able to compute the actual value of $t_{k}$.

Now, we can expand:

$$
\begin{gathered}
p_{k}(t)=\left\|P\left(X_{k}+t \Delta X_{k}\right)\right\|^{2} \\
=\left\|P\left(X_{k}\right)+t F_{X_{k}} \Delta X_{k}+t^{2} A\left(\Delta X_{k}\right)^{2}\right\|^{2} \\
=\left\|(1-t) P\left(X_{k}\right)+t^{2} A\left(\Delta X_{k}\right)^{2}\right\|^{2} \\
=(1-t)^{2}\left\|P\left(X_{k}\right)\right\|+t^{4}\left\|A\left(\Delta X_{k}\right)^{2}\right\|^{2}+t^{2}(1-t) \operatorname{trag} \times \\
\times\left(\left(P\left(X_{k}\right)\right)^{*} A\left(\Delta X_{k}\right)^{2}+\left(\left(\Delta X_{k}\right)^{2}\right)^{*} A^{*} P\left(X_{k}\right)\right) \\
=\alpha_{k}(1-t)^{2}+\gamma_{k} t^{4}+\beta_{k} t^{2}(1-t)
\end{gathered}
$$

where $\alpha_{k}=\left\|P\left(X_{k}\right)\right\|^{2}$,

$$
\beta_{k}=\operatorname{trace}\left(\left(P\left(X_{k}\right)\right)^{*} A\left(\Delta X_{k}\right)^{2}+\left(\left(\Delta X_{k}\right)^{2}\right)^{*} A^{*} P\left(X_{k}\right)\right)
$$

and $\gamma_{k}=\left\|A\left(\Delta X_{k}\right)\right\|^{2}$.

We can assume that $\alpha_{k}>0$ and $\gamma_{k}>0$.

Since $\gamma_{k}=0$, reduces $p_{k}(t)=\alpha_{k}(1-t)^{2}$, in which case $t_{k}=1$, which reduces to a normal Newton step.

Also, if $\alpha_{k}=0$ we come up with the solution.

The best value of $t_{k}$ can be found by solving numerically $p_{k}^{\prime}(t)=0$, and then checking at which collation of $p_{k}^{\prime}(t)=0$, function $p_{k}(t)$ attains its global minimum.

It has been shown that this modification of the Newton method converges quadratically as the original Newton method.

\section{Conclusion}

The discrete Lyapunov-like functional with a discrete convolution of delayed states was used for the stability investigations of finite time stability for a particular class of time discrete systems. The methodology used in the previous studies was to combine the Lyapunov-like approach and the Jensen's discrete inequality. The novel sufficient stability conditions were presented in a form of algebraic inequalities with a necessity of solving the particular quadratic (nonlinear) discrete matrix equation upon certain matrix $A$.

In general, this paper provides one possible solution to the same problem (as previously described) for a nonlinear matrix equation. The formulation of the matrix equation was done in a way that is able to perform the calculation using its factorization form. These results present a natural extension of the contributions presented in [7-12].

Some numerical methods have been presented in order to show their applicability to this problem. The numerical example is, also, included so that the computation could be demonstrated when the original, suggested procedure was used.

\section{References}

[1] DORATO,P.: Short time stability in linear time-varying system, Proc. IRE International. Conv. Rec. Part 4, New York, 1961, pp.83-87.

[2] WEIS,L., INFANTE,F.F.: Finite-time stability under perturbing forces and on product spaces, IEEE Transaction on Automatic Control, 1967, Vol.12, No.1, pp.54-59. 
[3] AMATO,F., ARIOLA,M., DORATO,P.: Finite-time control of linear systems subject to parametric uncertainties and disturbances, Automatica, 2001, Vol.37, No.9, pp.1459-1463.

[4] AMATO,F., ARIOLA,M., DORATO,P.: Finite-time stabilization via dynamic output feedback, Automatica, 2006, Vol.42, No.2, pp.337-349

[5] AMATO, F., ARIOLA, M.: Finite-Time Control of Discrete-Time Linear Systems, IEEE Transactions on Automatic Control, 2005, Vol.50, No.5, pp.724-729.

[6] AMATO, F., CARBONE, M., ARIOLA, M., COSENTINO, C. FiniteTime Stability of Discrete-Time Systems, Proceeding of the 2004 American Control Conference, Boston, Massachusetts, June 30 - July 2, 2004, pp.1440-1444.

[7] DEBELJKOVIC, D.LJ., LAZAREVIC, M.P., KORUGA, DJ., MILINKOVIC, S.A., JOVANOVIC, M.B.: Finite time stability of linear systems with delayed state, Scientific Technical Review, 2002, Vol. LII, No.3, pp.29- 32 .

[8] DEBELJKOVIC, LJ.D., STOJANOVIC, S.B.; Asymptotic Stability Analysis of Particular Classes of Linear Time-Delay Systems: A New Approach, Scientific Technical Review, ISSN 1820-0206, 2008, Vol.LVIII, No.1, pp.32-49.
[9] STOJANOVIC, S.B., DEBELJKOVIC, D. LJ., MISIC, M.A.: FiniteTime Stability Analysis of Discrete Time-Delay Systems Using a New Lyapunov-Like Functional with a Discrete Convolution of Delayed States, Acta Hungarica (2015) submitted.

[10] STOJANOVIC, S.B.. DEBELJKOVIC,D .LJ., MISIC, M.A., BUZUROVIC,I.M.: Finite-Time Stability Analysis of Discrete TimeDelay Systems Using Discrete Convolution of Delayed States, Automatika (Croatia) (2014) submitted.

[11] STOJANOVIC, S.B., DEBELJKOVIC, D.LJ., MISIC, M.A.: FiniteTime Stability for a Linear Discrete-Time Delay Systems by Using Discrete Convolution: an LMI approach, International Journal of Control, Automation and Systems, accepted: DOI: 10.1007/s12555014-0447-z

[12] BUZUROVIC,I., CVETKOVIC, A., DEBELJKOVIC ,D. Lj.: Delay Dependent Finite Time Stability of Discrete Time Delay Systems: Towards the New Solution, Proceedings of The International Conference on Applied Mechanics and Mechatronics Engineering (AMME 2015) October 25-26, 2015, Bangkok, (Thailand), CD - Rom

Received: 21.04.2015. Accepted: 20.07 .2015 .

\title{
Stabilnost na konačnom vremenskom intervalu, zavisna od kašnjenja, linearnih diskretnih sistema sa kašnjenjem: prilaz sa pozicija numeričkog rešavanja
}

\begin{abstract}
U ovom radu razmatra se jedno moguće rešenje bazične nelinearne kvadratne matrične jednačine. To rešenje ima krucijelni značaj u formulisanju posebnog kriterijuma, zavisnog od iznosa čisto vremenskog kašnjenja, za stabilnost na konačnom vremenskom intervalu posebne klase sistema sa kašnjenjem, opisane svojim matričnim modelom $x(k+1)=A_{0}(k)+A_{1} x(k-h)$. U tom smislu izveden je i odgovarajući kriterijum stabilnosti koji uključuje i iznos čisto vremenskog kašnjenja. Mimo toga, posebno je apostrofiran značaj nelinearnog diskretnog matričnog polinoma u stabilnosti sistema. Koristeći matematički formalizam, baziran na Traub-ovom i Bernuli-jevom algoritmu, zaključeno je da sračunavanje dominantnog solventa matričnog polinoma, ne garantuje potrebnu konvergenciju u svim slučajevima, kao što je slučaj u tradicionalnim numeričkim procedurama. U ovom radu, prezentuje se jedno posebno i jedno opšte rešenje, koje važi za slučaj kada se matrični polinom može prikazati u faktorizovanom obliku. Numeričkim primerom ilustrovana je opravdanost predložene procedure.
\end{abstract}

Key words: diskretni sistem, linearni sistem, sistem sa kašnjenjem, stabilnost sistema, sistem na konačnom vremenskom intervalu, diskretna matematika, partikularno rečenje, numerički rezultati.

\section{Stabilité sur l'intervalle temporelle finie dépendante du délai des systèmes linéaires discrets à délai: tableau de solution numérique}

\begin{abstract}
Dans ce papier on propose la seule solution possible pour l'équation non linéaire matrice de base carrée. Cette solution est d'importance cruciale pour formuler un critère particulier dépendant du délai pur temporel et pour la stabilité sur l'intervalle temporelle finie de la classe particulière du système à délai , décrite par son modèle matrice $x(k+1)=A_{0}(k)+A_{1} x(k-$ $h$. Dans ce sens on a dérivé un critère de stabilité correspondant qui comprend aussi le délai pur temporel. A part cela, on a souligné l'importance du polynôme discret de matrice non linéaire dans la stabilité du système. En utilisant le formalisme mathématique basé sur l'algorithme de Traub et Bernoulli on a conclu que la computation du solvant dominant du polynôme de matrice ne garantissait pas la convergence nécessaire dans chaque cas comme par exemple dans les procédures numériques traditionnelles. Dans ce travail on présente une solution particulière et aussi une solution générale valable pour le cas ou le polynôme de matrice se présente en forme factorisée. Au moyen d'un exemple numérique on a illustré la justification de la procédure proposée.
\end{abstract}

Mots clés: système discret, système linéaire, système à délai, stabilité de système, système sur l'intervalle temporelle finie, mathématique discrète, solution particulière, résultats numériques. 


\title{
Стабильность в системах конечного времени в зависимости от задержек, линейных дискретных систем со задержкой времени: дисплей с показом численных решений
}

\begin{abstract}
В этой статье рассматривается одно возможное решение основного нелинейного квадратного матричного уравнения. Это решение имеет важнейшее значение в разработке конкретных критериев, в зависимости от суммы чистых временных задержек, потом для стабильности в конечном интервале времени специального класса систем задержки, описанных их матричной моделью $\mathbf{x}(\mathbf{k}+1)=\mathbf{A 0}(\mathbf{k})+\mathbf{A 1 x}(\mathrm{k}-\mathrm{h})$. В этом смысле мы также проводили адекватный критерий стабильности, который включает и чистый объём временной задержки. Кроме того, особенно была подчёркнута важность нелинейного дискретного матричного многочлена в стабильности системы. Использованием математической модели описания, основанной на алгоритмах Трауба и Бэрнулли, был сделан вывод, что расчёт доминирующего растворителя матричного многочлена, не гарантирует необходимую сходимость во всех случаях, каков случай в традиционных численных процедурах. В этом исследовании представлены одно специальное и одно об̆щее решение, которые относятся к случаю, когда матричный многочлен можно представить в факторизованной форме. Численным примером показано обоснование предлагаемой процедуры.
\end{abstract}

Ключевые слова: дискретная система, линейная система, система с временной задержкой, стабильность системы, системы конечного времени, дискретная математика, особое частное решение, численные результаты. 